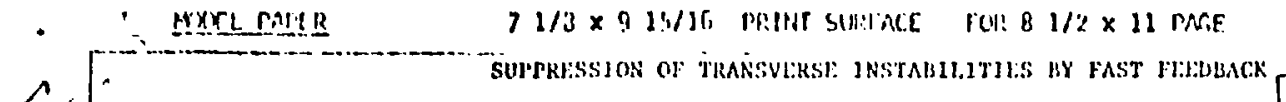

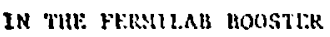

C. Ankenbrandt, F.F. HI f, In, Jr., and R.P. Johnson

feral National Accelerntor laboratory*
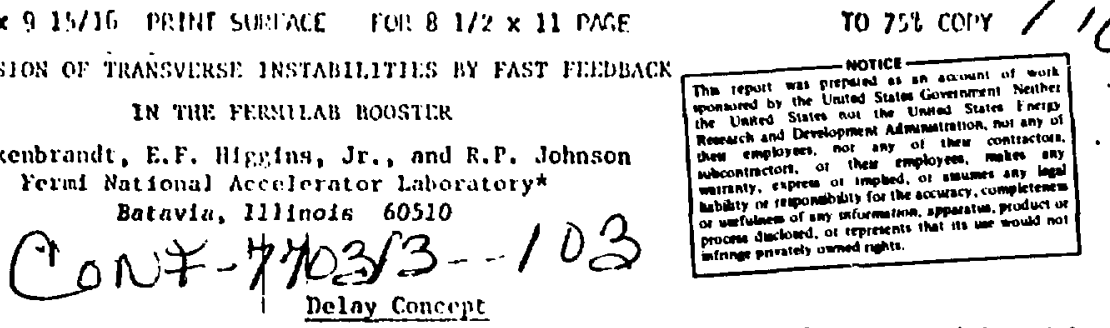

Summary

The rejul rements for a long and variable delay with

Systems to damp radial and vertical instabllitics iof Indivirual of bunches in the Fermllab Booster are beine implemented. The posittions of individual bunches are derived from stripline pickups. The position information is transmlted over a varlabje delay, nmplifled, and applied to deflectors after one almost complete revolution, 6.25 horirontal and 6.75 vertical betatron wavejengths downstream of the pickup. Mot1vation, system concepts, design considerations, and inftial operat 1ng experience are descrfbed here. Accompanying papers describe the electronics for signal processing and transmission.

\title{
Introduction
}

Systems to damp transwerse beam instablltics on a bunch-by-buach basis are being Implemented for the Fernllab Booster proton synchrotron. The najor purpose of the systems is to damp transverse hetatron oscillations of the centrutd of individual bunches, as can be caused by resistlve-wall instablities such as the head-tall-effect. The intensity at which such Instabllitics appear depends on the distance to the walls of the vacuum chamber. Thereforc, the system for the vertical coordinate was implemented first. It has been in use for a few months and intial operating experlence will be described here. The radial system araits the completion of its electronlcs, cxpected by June.

\section{Design of the Systems}

\section{Booster Tining Constderation:}

The revolution frequency and the RF frequency of the Booster strongly influenced the design of the systems. The circumference $C$ of the Booster is 474.4 meters. As the kinetic energy increascs from $200 \mathrm{NeV}$ to $8 \mathrm{GcV}$ between injection and extraction, the velocity of the-protons increases from .57 to $.99 \mathrm{c}$. Therefore, the revolution period $T_{\text {rev }}$ decreases from 2.8 to 1.6 usec. Since the acflectors are almost a full revolution downstream of the pickups, the position information aust be stored for corresponding durations before application to the deflectors.

The radio frcquency accelcrating systion of the Booster operates on the $84 \mathrm{th}$ harmonic of the revalution frequency, varying from 30 to 53 aliz as it forms and accelerates $h=84$ bunches of protons. The spacing between bunches is then $\mathrm{C} / \mathrm{h}=5.56$ meters, and the time interval between bunches, $T_{\text {rev }} / h=t_{r f}^{-l}$, varies

fron 33 to 19 usec during the acceleration cycle. The reed for the signal on the deflecting electrodes to change from one correction signal to the next in the Interval between bunches thus led to an upper limit of - few nsec ror rise and fall times and timing errors for the whole system. Although the time between bunches Is longer carly in the excle, the bunch length is also longer (in fact the hean is agitially unbunched), so that comparable timing requirements exist throughout the cycle after the beam is bunched. simultancous st orage of position information for about
84 bunches led us to choose a cabla-delay system with fast electronic switches to vary the delay. This concept is modeled after that of the Argonnc ZCS domper system, but the of frequency is much hifher in our case and the ifinfing requirements correspondingly more stringent. Briefly, the delay works as follows. There are rine delay cables for each system (radjal and vertical) whose clectrical lengths ${ }^{3}$ forta a binary gcometrical progression $\mathrm{T}_{\mathrm{m}}=2^{\text {th }} \mathrm{T}_{0}, 0 \leq \mathrm{m} \leq 8$. A binary logic system digitizes the of frequency, and the binary bits of the result determine which cables to switch into the delay path. The system is fated off for 3 usec during the swlteling transients. Digitizing the of frequency generates a binary nulaher $\mathrm{B}$ proportional to the colal required delay $T_{d}$, but becausc there are unavoldahle fixed delays $T_{f 1 x}$ in the system, a subtraction is required so that the variable delay $T_{\text {var }}=T_{d}-T_{f i x}=$ $B T_{0}-T_{f 1 x}$. The subtraction is simplified in these systems by adding a long cable so that $T_{f 1 x}=512 \mathrm{~T}_{0^{\circ}}$ Then the subtraction is accomplished by merely fgnoring the most significant bit of $B$. The fact that the frequency swing during acceleration is less than a factor of toc maksi this irick possible. The shortest cable length, $\mathrm{T}_{0}$, is about $2.7 \mathrm{nsec}\left(\mathrm{T}_{0}=2.615 \mathrm{nscc}\right.$ radially, 2.730 nsec vertically) so that the variable delay switches its length about 450 times in 2,7 nsec steps during the 33 msec Booster acceleration cycle to cover the range from 2.8 to $1.6 \mathrm{\mu sec}$. The system is gated off a total of about $4 \%$ of the time during these switching intervals, rostly near the beginning of the cycle.

\section{Functional Description}

The design of the rest of the electronics was largely influenced by this choice of delay system. A functional block diagram of the vertical system is shown in F1g. 1; the radial system will be essentially identical. The proton beam passes through an enclosure containing 4 stripline pickups, two for each coordinate. The striplines are $50 \Omega$ transmission lines; and cach output is bicught up from the tunnel on $50 \Omega$ cables, through attenuators to balance the signals when the beam is on the desired orbit, to a fast position detector. The electronics for the systen is described in detail in another paper submitted to this conference; 5 here only a brief outline of the electronics will be presented. The position error signal is decomposed into magnitude and polarity, and the two signals are transmited ${ }^{6}$ over the delay system using an amplitude medulation sclieme on two different carrier frequencles. Finally the correction signal is applied through commercial RF power ampliflers (Instruments For Industry) to the deflection electrodes.

The power capability of about 100 Watts is such that a transwarse momentum of about $10 \mathrm{keV} / \mathrm{c}$ can be generated per pass. With the galns currently in use, position error of about one fallimeter generates this maximum transverse momentum. Beyond this point the RF power amplifiers sacurate.

tOperated by liniversitles Research Association Inc. under contract whth the Energy and and

pevelopment Aduninistrap

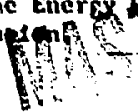




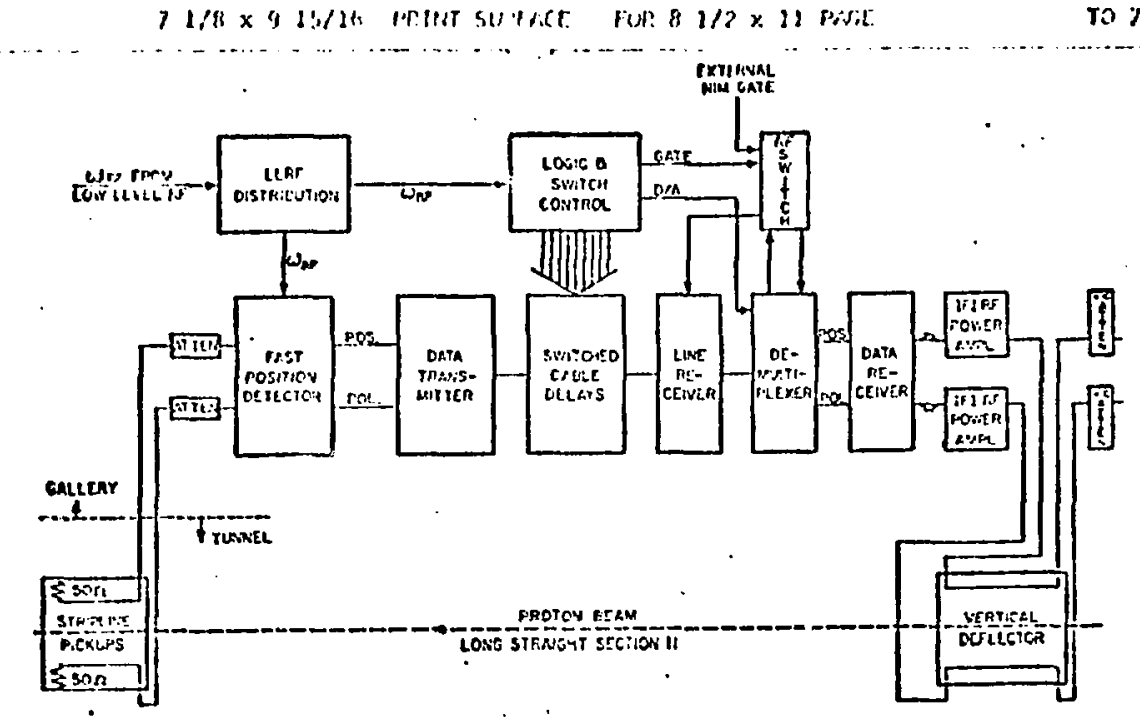

F1g. I Block diagram of the najor functional components of the vertical superdamper.

detected pesilion error has hecome an angle error, 1.e. $(2 \mathrm{n}+1) / 4$ betatron wavelengths downstream of the pickup. The vertical deflector is 6.751 downstrean (the vertical tune $v_{v}$ is 6.8 ) and the horizontal deflector is $6.25 \lambda$ downstrear $\left(\nu_{j}=6.65\right)$. The pickups and vertical deflector are in Long Straight Section 11 and the hrolzontal deflector is in Long 10 .

\section{Opcrational fisperience}

\section{Initial Comissioning}

In early tests of the vertical superdaniper system, betatron oscillations induced by pinging the beam were observed to damp approxicately exponentially, as shown in Fig. 2, with a tive constant of about $200 \mathrm{usec}$, corresponding to about 100 turns, at a momenturn of 1.5 GeV/c. This damping tine agrees with that expected from the gain of the system, within the errors.

The system was also tested in the antidamping mode by merely interchanging the drive signals for the amplifiers feeding the two deflector plates. In this mode benm losses can be induced; it takes about 2 msec carly in the cycle to destroy most of the beam. This Is considerably longer than the damping tine, probably because of the sacuration of the $r f$ power amplifiers for position crrors greater than about a millimeter. The antidamping mode provides a sensitive way to determine the optinum fixed delay by means of a cable dclay curve. In this way it was verified that the variable delay system correctly tracks the protonveloc1ty. Another simple test of the system was the re'duction In "fuzz" on the position error signal by almost in order of magnitude when the feedback loop was closed, as can be seen in Fig. 3 .

An unpleasant surprise in early operation was the censitivity of the system's perforinance to the position of the beam at the pickups. It was subsequently realized that gating the system to zero durlng switching transieuts constitutes a beam kick unless the error oIponal happens to be zero hofore being gited off. In the vertical system this effect is not too serlous and Is current Iy controlled by means of balanctup attenum latora and a nc. heam buap at the pickups. Radlally I more heam mot ion occurs, and a track-and-hold feature Is being Incorporated to furnish a sow moving average

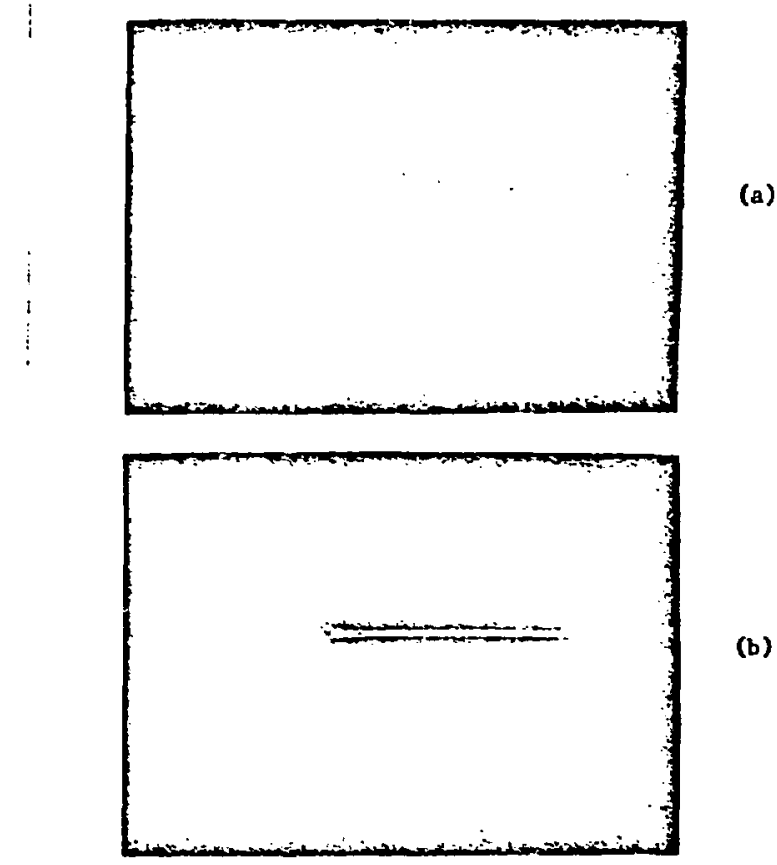

Fig. 2 Coherent vertical betatron oscillations induced by a pulsed magnet wh the superdamper (a) off, (o) on.

that can be suitched to during switching transients.

\section{Present Operation}

The simplest theory of the head-tall-effect' provides a framework in terms of which our early operating experfence with the vertical superdamper can at least be Intelligently discussed if not always completely understood. The theory predicts a growth rate $B$ for Instabilitfes (in the absence of active damping) proportional to

$$
B \propto \frac{d v}{d p}\left(\frac{1}{\gamma^{2}}-\frac{1}{r_{t}^{2}}\right)^{-1}\left(1-4 m^{2}\right)^{-1}
$$




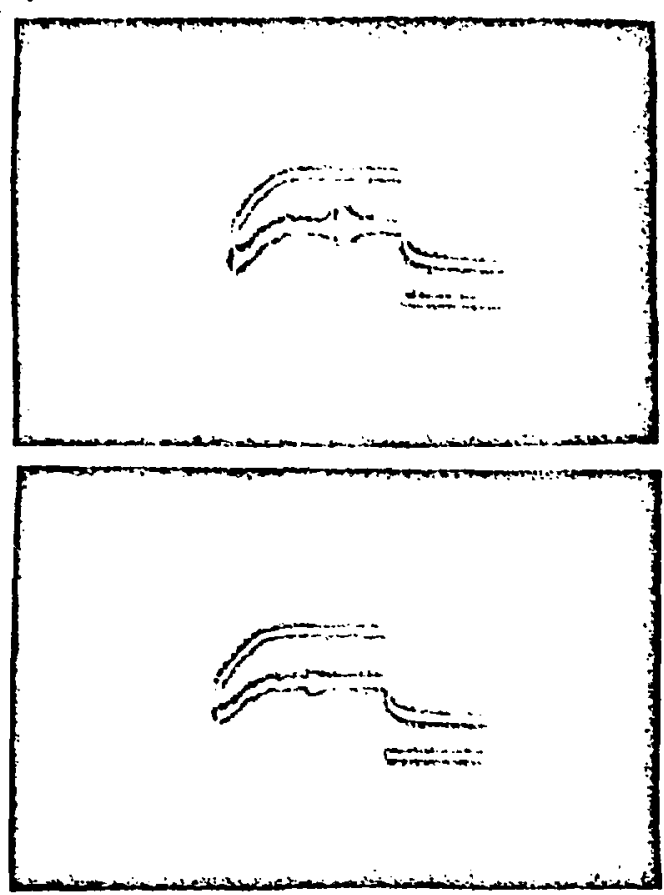

F1g. 3 The botton trace in each photo is the position error signal; the top trace is the beam current with superdamper (a) off (b) on,

where $\frac{d v}{d p}$ is the chromaticity or rate of change of tune with momenture and $w$ is the mode number of the bunch shape, $t=0$ corresponding to motion of the bunch centroid. If $B$ is negative the instability is damped. The theory then predicts that controid motion $(a=0)$ will have the lowest threshold and that the chromaticity required for passive damping will change sign at the transition energy.

Before the vertical system was installed, headtail effects were lessened by programed sextupoles in stralght sections. Best results were obtained when the sextupoles in the long straight sectlons, which primar$11 y$ affect the vertical chromaticity, were ramped to give a nonzero chronaticity except when it changed sign near transition time, in agreement with the formalism outlined above.

With the active superdamper to control head-tall effects, the long straight sextupoles can now be ramped in order to zero the vertical chromaticity throughout the Boostcr cycle, leading to presumably larger goodficld apcrture. Some small gains in transmisstonhave resulted from this mode of operation. In fact it is even possible to accelcrate up to about $10^{12}$ protons per Booster cyclc with the long straight sextupoles of $f$ which causes opposite-sign chromaticitics that strongly ant idamp early in the cycle.

It was discovered empirically that transmission can be ioproved at high intensity by gating the vert1cal damper of for the first two isec of the cycle and for about live msec around transition tine. Because of tune spread, coherent oscillations rapidly lead to emittance growth. It is belleved that some enittance growth early in the cycle may be destrable in order to mintmize space-charge tune shifts.

The explanation of the gate around transition time
Is more surprising. It was discovered thit if the vertical duper is left an throuph irantitlon, gudlal. blowup ensile:: thereafer: Coherent bunch-by-bunch radial Instahllitles ware directly observed (cf. Ftg.t4) os well as larper radlal beam size in the extraction 1ine. If the damper is pialed off, on the other hand, some vertelal blowup occurs near transit lon time, and for sone riason thls prevints the nore serfous radial blowup. He thus look forward to the complnt lon of the radial system to derive full beneflt from the dampers. In the meatut fine optimil results are obraincd with a radjal position curve that results in a radial chromaticlly ilat causes passive damping throughout the cycle. In particular this nicans a rapid radial totion through trithitition.

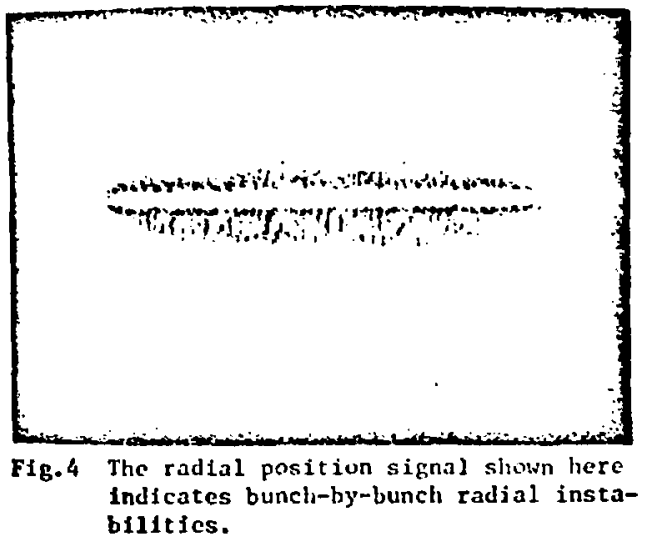

\section{Acknowledgements}

It is a pleasure to acknowledge the many contributions of Booster group members, in particular $J i a$ Griffin, Keith Neisner, and Gil Nicholls, to the development of these systems. Discussions with quentin Kerns were very useful in the design of pickups and deflectors. The operations crew in the main control room, and particularly Jim Lackcy, helped significantly in the optimization of the vertical damper system.

\section{References}

1. A.G. Ruggiero, "The Head-Tail Ef fect in NaL Booster", Fermflab FN-248, 1972 and private communication.

2. R.H. Hilden, J.H. Martin, F.E. MIlls, and R.A. Hinje, "Apparatus for Damping Axlal Coherent Beam Instabilities in a Synchrotron Particle Accelerator", U.S. Patent No. 3,378,778.

3. Gil Nicholls, "Precisely Measuring the Electrical length of Coax Cables", Fermilab TM-711, 1977.

4. B.R. Sandberg, "Logle and Control System for the Fermtlab Booster Beam Damper", submitted to this conference.

5. E.F. Higgins, Jr., "Electronies for Damping Transverse Instabilities for the Ferwilab Booster Synchrotron", submitted to this conference.

6. S. Jachim, "A High-Speed RF Data Transtaitter for the Fermilab Booster Ream Damping System". subaitted to this conlerence. 